\title{
Multifunctional Nanoplatform for Targeted Laser-induced Hyperthermia and Microscopy of Breast Cancer Cells using SPION-based Gold and Folic Acid Conjugated Nanodendrimers: An in vitro Assay
}

Khosroshahi ME*1,2,3 and Tajabadi $\mathbf{M}^{1,4}$

${ }^{1}$ Amirkabir University of Technology, Faculty of Biomedical Engineering, Biomaterial Group, Laser and Nanobiophotonics Lab., 15857-4413, Tehran, Iran

${ }^{2}$ University of Toronto, Department of Mechanical and Industrial Engineering, Toronto, ON M5S 3G8, Canada

${ }^{3}$ MIS-Electronics, Nanobiophotonics and Biomedical $R$ and D Center, Richmond Hill, ON L4B 1B4, Canada

${ }^{4}$ Iran University of Science and Technology, School of Metallurgy and Materials Engineering, Narmak, 16846-13114, Tehran, Iran

\begin{abstract}
The use of nanotechnology seems to be a promising approach for early detection, imaging and therapy of cancer. In this investigation, $9 \mathrm{~nm}$ superparamagnetic iron oxide nanoparticles (SPION) were synthesized and functionalized by third generation polyamidoamine (G3-PAMAM) dendrimer. The magnetodendrimer samples were then conjugated by folic acid molecules for targeting and by gold nanoparticles for photothermal hyperthermia purpose. The gold nanoparticles were synthesized using three reducing agents of sodium borohydride, hydrazine sulfate and presynthesized 10-nm AuNPs. The final nanocomposite is named IDAF NC (Iron oxide-Dendrimer-Gold-Folic acid). Two breast cancer cell lines of MDA MB 231 and MCF 7 were used for cytotoxicity, uptake and photothermal assay. The results confirmed that AuNPs prepared by sodium borohydrate and the pre-synthesized 10-nm AuNPs were larger and those prepared by hydrazine sulfate were smaller and uniformly entrapped within dendrimer cavities. The MDA MB 231-IDAF-Hydr combination exhibited the highest viability percentage at $50 \mu \mathrm{g} / \mathrm{mL}$ before laser irradiation and lowest cancer cell viability of $65 \%$ (i.e., highest cell apoptosis and crystallization after irradiation).
\end{abstract}

Keywords: Magnetodendrimers; Gold nanoparticle; Folic acid; Breast cancer; Laser hyperthermia; Theranostic

\section{Introduction}

Cancer is a major public health problem which causes high rate of morbidity and mortality worldwide. It is well known that cancer therapy relies on chemotherapy and radiotherapy where most anticancer drugs are essentially taken up by cells with high proliferative rate, a distinct cancer cell characteristic. During the treatment process, however, normal tissue also suffers from chemotherapeutic actions, causing severe side effects $[1,2]$. Theranostic nanoparticles are multifunctional nanosystems, which are fabricated for such a task in a single biocompatible and biodegradable nanoparticle $[3,4]$. Small magnetite nanoparticles $(<15 \mathrm{~nm})$ is called superparamagnetic iron oxide nanoparticle (SPION), which lacks a hysteresis loop and possess high field irreversibility, high saturation field and extra anisotropy contributions [5,6]. Over the past decades SPIONs with size and morphology dependent physical and chemical properties including biocompatibility, chemical composition, magnetic behavior, surface structure, adsorption properties, solubility, low toxicity, good magnetic response have attracted world-wide research attention $[7,8]$. These unique materials have been utilized successfully for number of applications including contrast-enhanced imaging [9] and drug delivery [10]. In magnetically guided nanoparticles (NPs), a constant external magnetic field is used to transport magnetic NPs loaded with drugs to a specific site within the body or to increase the transfection capacity. Functional groups play an important role in the production of organic shell around inorganic core to prepare uniform and stable suspension. Basically, a dendrimer is composed of three architectural components: a core (I), an interior of shells (generations) consisting of repeating branch-cell units (II), and terminal functional groups (the outer shell or periphery) (III) [11,12]. One such example is poly (amidoamine) (PAMAM), which acts as a template or stabilizer for preparation of inorganic nanocomposites. Dendrimers, especially PAMAM are capable of conjugating targeting ligands, imaging agents and drug molecules for targeted therapeutics. Intrinsic fluorescence of dendrimer as surface modification can reduce the need for external fluorescent carrier, hence the final biocompatibility of delivery system will be improved $[13,14]$. The concept of dendrimer nanocomposites is based on immobilization of pre-organized metallic ions [15]. Thus, a dendrimer acts as a template or reactor to pre-organization of ions and small molecules [16]. In such cases, atoms and molecules could attach to internal space or external surface of dendrimer [17,18]. Plasmonic nanoparticles exhibit unique optical properties such as strong localized surface plasmon resonance (LSPR), surface-enhanced scattering, nonlinear optical properties, tunable resonance across the Vis-NIR due to adjustable nanoparticle size and shape [19-23], biocompatibility due to their inert surface, nontoxicity, surface conjugation chemistry i.e., they can be linked to specific ligands for tumor targeting, imaging and therapies, lack of photobleaching or blinking as with quantum dots, and very low oxidation [24,25]. As a result, AuNPs, nanoshells or nanorods have been extensively utilized for bioimaging [26,27], cancer cell diagnostics and therapeutics $[28,29]$. In addition to enhanced permeation and retention (EPR) effect in passive targeting, tumor cells show higher concentration of receptors on their surfaces related to their enhanced mitosis rates. Thus, these receptors can be suitably targeted for active targeting by binding with for example ligands or antibodies. Folate binding proteins can be classified as low-affinity

*Corresponding author: Mohammad E. Khosroshahi, MIS-Electronics, Nanobiophotonics and Biomedical R\&D Center, Richmond Hill, ON L4B 1B4 Canada, Tel: 9057072305; E-mail: khosrom@mie.utoronto.ca

Received: February 24, 2017; Accepted: March 15, 2017; Published: March 22 2017

Citation: Khosroshahi ME, Tajabadi M (2017) Multifunctional Nanoplatform for Targeted Laser-induced Hyperthermia and Microscopy of Breast Cancer Cells using SPION-based Gold and Folic Acid Conjugated Nanodendrimers: An in vitro Assay. J Nanomed Nanotechnol 8: 432. doi: 10.4172/2157-7439.1000432

Copyright: (c) 2017 Khosroshahi ME, et al. This is an open-access article distributed under the terms of the Creative Commons Attribution License, which permits unrestricted use, distribution, and reproduction in any medium, provided the original author and source are credited. 
Citation: Khosroshahi ME, Tajabadi M (2017) Multifunctional Nanoplatform for Targeted Laser-induced Hyperthermia and Microscopy of Breast Cancer Cells using SPION-based Gold and Folic Acid Conjugated Nanodendrimers: An in vitro Assay. J Nanomed Nanotechnol 8: 432. doi: $10.4172 / 2157-7439.1000432$

Page 2 of 11

binders consisting of the reduced folate carrier and responsible for the majority of folate transport across cell membranes and high-affinity binders consisting of the folate receptor (FR) that mediate folate uptake by endocytosis. Three distinct FR isoforms are referred to as FRa, FR $\beta$, and FR $\gamma$ - each with tissue-specific distribution and folate binding potential. Receptors involved in endocytotic activity provide a pathway for the nanoparticles to be accumulated within the cells rather than being restricted to the surface.

From a photothermal therapy perspective, the wave length of maximal absorption and the absorption cross-section are key features to consider when selecting a particle for hyperthermia. It is suggested if the temperature increases to about $42-45^{\circ} \mathrm{C}$ from the physiological temperature of $37^{\circ} \mathrm{C}$, the induced heat heat can effectively destroy the cancer cells via cell-targeted uptake [30]. Meanwhile, size and surface characteristics of the nanoparticle are of prime importance in the biodistribution and rapid clearance of nanoparticle from the blood which affects nanoparticle delivery to target sites [25,31]. In recent years much interest has been shown for nanotechnology-based hyperthermia and effective cancer therapy where one of the main goals of is to deliver therapeutic agents to tumor sites, since most anticancer drugs cannot distinguish between healthy and cancerous tissues hence causing some undesirable results [32-35]. In our previous study, application of doxorubicin loaded magnetic thermosensitive liposomes for laser hyperthermia and chemotherapy of breast cancer was reported [36].

In this investigation, we designed a novel targeted multifunctional probe utilizing SPOIN-based nanodendrimers for bioimaging and photothermal applications as illustrated in Scheme 1. Gold nanoparticles were conjugated for therapeutic purpose and folic acid (FA) ligand was selected as targeting molecule for number of reasons: a) Nutrients pathways are attractive because they are directly linked to proliferation and thus in principle will cause increased uptake, b) FA receptors are overexpressed in several human carcinomas including breast, ovary, lung [37,38]. Following our previous work [39] on viability of L929 and MCF7 cells using iron oxide-dendrimer (ID) complex, we report the results of i) Synthesis and characterization of SPION-PAMAMAuNP-FA nanocomposites hereafter is referred as (IDAF-NC) using sodium borohydrate and hydrazine sulfate as reducing agents, and presynthesized AuNP. The purpose of this part was to study the effect of synthesis technique on the properties of NPs such as size and thus its effect on the imaging and therapy, ii) Evaluation of cytotoxicity and uptake of IDAF-NC by MDA MB 231 and MCF 7 breast cancer cell lines and iii) Evaluation of laser irradiation of IDAF-NC after uptake.
Figure 1 represents schematically the cellular uptake of gold and folate receptor-conjugated magnetodendrimer followed by laser irradiation for bioimaging and photothermal therapy.

\section{Materials and Methods}

Ferric chloride hexahydrate $\left(\mathrm{FeCl}_{3} \cdot 6 \mathrm{H}_{2} \mathrm{O}, 99 \%\right)$, Ferrous sulfate heptahydrate $\left(\mathrm{FeSO}_{4} \cdot 7 \mathrm{H}_{2} \mathrm{O}, 99 \%\right.$, andEthanol $\left(\mathrm{C}_{2} \mathrm{H}_{5} \mathrm{OH}\right)$ were purchased from Merck Company. Ammonium Hydroxide $\left(\mathrm{NH}_{4} \mathrm{OH}\right)$, Methyl Acrylate $\left(\mathrm{CH}_{2}=\mathrm{C}\left(\mathrm{CH}_{3}\right) \mathrm{COOCH}_{3}\right)$, Ethylenediamine $\left(\mathrm{C}_{2} \mathrm{H}_{4}\left(\mathrm{NH}_{2}\right)_{2}\right)$, Sodium Borohydrate $\left(\mathrm{NaBH}_{4}\right)$, Hydrazine sulfate $\left(\mathrm{H}_{6} \mathrm{~N}_{2} \mathrm{O}_{4} \mathrm{~S}\right)$, Gold colloid solution $(10 \mathrm{~nm})$, Folic Acid $\left(\mathrm{FA}, \mathrm{C}_{19} \mathrm{H}_{19} \mathrm{~N}_{7} \mathrm{O}_{6}\right)$, Dimethyl Sulfoxide (DMSO, $\mathrm{C}_{2} \mathrm{H}_{6} \mathrm{OS}$ ), Dimethyl Form amide (DMF, $\mathrm{C}_{3} \mathrm{H}_{7} \mathrm{NO}$ ), 1-)3-(dimethylamino)propyl(-3-ethylcarbodiimide $\mathrm{HCl}, \mathrm{C}_{8} \mathrm{H}_{18} \mathrm{ClN}_{3}$ EDC), (3-(4,5-dimethylthiazol-2-yl)-2,5-diphenyltetrazolium (MTT), Fetal Bovine Serum (FBS) were obtained from Sigma (USA). Presynthesized gold nanoparticles (AuNPs) were purchased from sigma Aldrich.

\section{Conjugation of magnetodendrimer complex with AuNPs (IDA)}

Following our previous reports on preparation of dendrimer functionalized SPION (ID) $[40,41]$, we describe the results of conjugation of magnetodendrimer complex with AuNPs as plasmonic photothermal source and folic acid as targeting agent (IDAF). The AuNPs were synthesized using three different reducing agents: (i) sodium borohydrate (IDA-NaBH ${ }_{4}$ ), (ii) hydrazine sulfate (IDA-Hydr), and (iii) gold nanoparticles (IDA-NP).

Sodium borohydrate as a reducing agent (IDA- $\mathrm{NaBH}_{4}$ ): $\mathrm{A}$ solution of tetracholoroauric acid $\left(\mathrm{HAuCl}_{4}\right)(5 \mathrm{mM})$ was prepared and added to the suspension of third generation ID $(1 \% \mathrm{w} / \mathrm{v})$ with the same volume under $\mathrm{N}_{2}$ atmosphere. In order to produce the complex between $\mathrm{Au}$ (III) and amide or amine group of dendrimer, the resulting mixture was vigorously stirred for one hour at darkness. After that, $5 \mathrm{~mL}$ of aqueous sodium borohydrate solution $(0.1 \mathrm{M})$ was added drop wise to the reaction mixture. The following reactions lead to reducing $\mathrm{Au}$ (III) to zero charge $\mathrm{Au}(0)$ nanoparticles. The reaction was continued under a vigorous stirring for 2 hours at $25^{\circ} \mathrm{C}$. The obtained NPs are referred as IDA- $\mathrm{NaBH}_{4}$. These particles were rinsed with ethanol five times using magnetic separation. The same procedure was repeated with the tenfold concentration of $\mathrm{HAuCl}_{4}$ and in order to evaluate the completion of the reactions, a UV-Vis analysis was performed at 0,15 ,

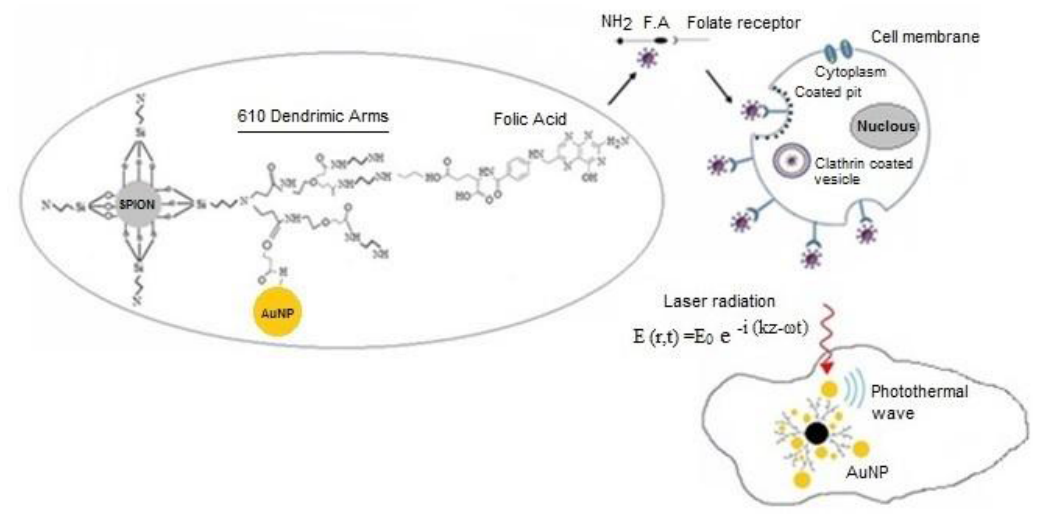

Figure 1: Schematic illustration of cellular uptake of gold and folate receptor-conjugated magnetodendrimer for photothermal therapy. 
Citation: Khosroshahi ME, Tajabadi M (2017) Multifunctional Nanoplatform for Targeted Laser-induced Hyperthermia and Microscopy of Breast Cancer Cells using SPION-based Gold and Folic Acid Conjugated Nanodendrimers: An in vitro Assay. J Nanomed Nanotechnol 8: 432. doi: $10.4172 / 2157-7439.1000432$

Page 3 of 11

$30,45,60,90$, and 120 minutes after addition of reducing agent. The product is referred to as (IDA-10).

Hydrazine sulfate as a reducing agent (IDA-Hydr): The stable $\mathrm{Au}$ NPs were produced by adding hydrazine sulfate $\left(\mathrm{H}_{6} \mathrm{~N}_{2} \mathrm{O}_{4} \mathrm{~S}\right)$ aqueous solution $(25 \mathrm{mM})$ to the solution of magnetodendrimer- $\mathrm{HAuCl}_{4}$ complex and stirring it for 2 hours. The particles were rinsed with ethanol five times as before and the final sample is referred to as (IDAHydr).

Gold nanoparticles (IDA-NP): AuNPs were directly added to MD suspension under $\mathrm{N}_{2}$ atmosphere. The mixture was stirred for an hour to complete the reaction and then particles rinsed five times with ethanol. The obtained magnetic product was then collected by magnetic separation and washed twice with ethanol to remove the physically adsorbed surfactant on the particle. The resulted sample is referred to as (IDA-NP). The bond between AuNPs and dendrimers is formed as a results of interaction between coordinating groups such as $-\mathrm{OH},-\mathrm{NH}_{2}$, or $-\mathrm{COOH}$ and gold ions.

\section{Conjugation of Gold-magnetodendrimer (IDA) Complex with Folic Acid (IDAF)}

Magnetodendrimer-gold (IDA) complex was functionalized via carbodiimide reaction with terminal amino groups. An amount of $0.085 \mathrm{mmol}$ of folic acid and $1.22 \mathrm{mmol}$ of EDC with molecular weight of $191.7 \mathrm{gmol}^{-1}$, which is generally used as a carboxyl activating agent for the coupling of primary amines to yield amide bonds, with the molar ratio of 1:14 (Fa/EDC) were reacted in the solution consisting of $27 \mathrm{~mL}$ of DMF and $9 \mathrm{~mL}$ of DMSO under $\mathrm{N}_{2}$ atmosphere for an hour. This organic mixture was added drop-wisely to aqueous mixture of $\mathrm{MD}-\mathrm{Au}$ complex and stirred continuously for 3 days. The final nanoparticles were purified using magnetic separation and centrifugation.

\section{Characterization}

An X-ray diffractometer ( $\mathrm{Cu} \mathrm{Ka,} \lambda=1.5406 \AA$, FK60-40) was used to determine the crystalline phase of NPs. Magnetic properties of the samples were measured by vibrating sample magnetometer (VSM-PAR 155) at $300 \mathrm{~K}$ under magnetic field up to $8 \mathrm{KOe}$ ). The bond formation between SPION-PAMAM-folic acid was confirmed by Fourier transform infrared (FTIR) spectroscopy (BOMEM, Canada). Particle size and morphology of the nanoparticles were determined by transmission electron microscopy (TEM, Philips CM200-FEG microscope, $120 \mathrm{KV}$ ). The distribution of IDAF in cells was quantitatively analyzed by Wavelength-dispersive X-ray spectroscopy (SEM-WDX, XL30, Philips-USA). In-vitro assays were performed using MTT, nanoparticles cellular uptake and laser microscopy (Zeiss Axioshop-Germany. The Fe content of cells after uptake in each well was measured using JENWAY 6305 UV/Vis Spectrometer. Finally, the cytotoxicity effects of IDAF before and after laser irradiation was studied by an optical microscope (INV-2, BEL-Italy).

\section{In-vitro tests}

Cytotoxicity evaluation: MDA MB 231 and MCF 7 (human breast cancer) cell lines were obtained from the National Cell Bank of Iran (NCBI, Pasture Institute of Iran). The cells were cultured in RPMI 1640 (GIBCO, USA) supplemented with $10 \%$ fetal bovine serum (FBS, GIBCO, USA) and seeded onto a 96 well-plate at a density of $15 \times 10^{3}$ cells per well in $100 \mu \mathrm{L}$ of medium at $37^{\circ} \mathrm{C}$ in a $5 \% \mathrm{CO}_{2}$ incubator for $24 \mathrm{~h}$. Serial dilutions of NPs $(5 \mu \mathrm{g} / \mathrm{mL}-250 \mu \mathrm{g} / \mathrm{mL})$ were then added to each well. The control well represented the cells in culture medium without any nanoparticles. After $24 \mathrm{~h}$ of incubation of cells with
IDAF-NP samples, all culture medium was removed and replaced by $100 \mu \mathrm{l}$ of MTT (3-(4,5-dimethylthiazol-2-yl)-2,5-diphenyltetrazolium bromide, Sigma-USA). After $4 \mathrm{~h}$, the formation of formazan crystals was checked by optical microscope and the supernatant removed. In order to dissolve formazan crystals, $100 \mu \mathrm{l}$ of isopropanol was added to each well and they were placed inside an incubator (Memmert-GmbH) for 15 minutes. The absorbance of each well was read using microplate reader (stat fax-2100, AWARENESS, Palm City, USA) at $545 \mathrm{~nm}$. The results were reported in the form of relative cell viability compared to control sample (which could be calculated by the following equation):

$$
\% \text { Viability }=\frac{A_{545}(\text { magnetic sample })}{A_{545(\text { control })}}
$$

Cellular Fe content evaluation: For this purpose, $1 \times 10^{4}$ cells per $\mathrm{mL}$ of culture medium were seeded in 12 well-plate $24 \mathrm{~h}$ before addition of nanoparticles. $100 \mu \mathrm{L}$ of each samples: ID (G3), IDAF$\mathrm{NaBH}_{4}$, IDAF-Hydr., IDAF-10, and IDAF-NPs with concentration of 50,100 and $250 \mu \mathrm{g} / \mathrm{mL}$ were added to each wells and samples were incubated for 24 at $37^{\circ} \mathrm{C}$ in a $5 \% \mathrm{CO}_{2}$ incubator and after this time, the supernatant solution was extracted and placed in a fresh 96-well plate at the same position (the absorption of this sections is reported as an 'unreacted' particles). At the second stage, the plate was incubated for 24 hours and after that, the cells were washed with $100 \mu \mathrm{L}$ fresh PBS and the resultant solution was placed into another fresh 96-well plate (the absorption of these wells were reported as a 'loosely attached' particles). Finally, the cell membrane was dissolved and the resultant absorption reported as particles taken up by the cells. Since, the iron oxide nanoparticles have characteristic maximum absorption in the range of 350-400 $\mathrm{nm}$, thus the supernatant UV-Vis absorption of samples were read at 3 major characteristics peaks of $\mathrm{Fe}_{3} \mathrm{O}_{4}$ at 320,355 and $370 \mathrm{~nm}$ to evaluate Fe content of cells in each well using calibration curves [39]. The absorption was read using JENWAY $6305 \mathrm{UV} / \mathrm{Vis}$ Spectrometer. The Fe content (\%) was measured by following equation:

$$
\text { Fe content } \%=\left(\frac{I_{\text {test }}}{I_{370 \text { control }}}\right) \times 100
$$

Here, $\mathrm{I}_{370}$ (Control) is the absorption regarding supernatant of control samples at $370 \mathrm{~nm}[42,43], \mathrm{I}_{\text {test }}$ is the supernatant absorption of cells which contain magnetic nanoparticles after addition of acetic acid.

SEM and WDX analysis of cultured cells: The MDA MB231 cells were cultured on coverslips placed in a 12 well plate. After $24 \mathrm{~h} 100$ $\mu \mathrm{g} / \mathrm{mL}$ of ID (G3), IDAF-NaBH ${ }_{4}$, DAF-Hydr, IDAF-10, and IDAFNP were added to each well and incubated for further 24 hours. The cells were fixed at $4 \%$ glutaraldehyde (Sigma, UK) solution in PBS at room temperature for $1 \mathrm{~h}$. The cellular uptake of NPs at different synthesis conditions were studied by SEM (XL30, Philips, USA). In addition, wavelength dispersive X-Ray analysis (WDX, Philips, USA) was performed to observe map distribution of NPs attached to the cells based on Fe element.

Cellular uptake study by fluorescent microscopy: Since, MD and IDAF NCs exhibit intrinsic fluorescence property; this can be used to investigate the NPs cellular uptake. For this, $1 \times 10^{4}$ MDA MB231 cells were seeded on coverslips following the addition of nanoparticles. After $24 \mathrm{~h}$, the medium was removed, the cells rinsed with PBS and the fluorescent emission of cells containing nanoparticles was detected by fluorescence microscope (Axioscop, Zeiss, Germany).

Laser irradiation and hyperthermia: Considering that IDAFHydr NC showed highest cellular uptake and MDA MB231 cells have 
Citation: Khosroshahi ME, Tajabadi M (2017) Multifunctional Nanoplatform for Targeted Laser-induced Hyperthermia and Microscopy of Breast Cancer Cells using SPION-based Gold and Folic Acid Conjugated Nanodendrimers: An in vitro Assay. J Nanomed Nanotechnol 8: 432. doi: $10.4172 / 2157-7439.1000432$

Page 4 of 11

higher tendency to vitamins of folic acid compared to MCF 7 cells due to abundancy of folate receptors at the surface of membrane, these cells were used for hyperthermia evaluation using $514 \mathrm{~nm}$ wavelength of tunable argon laser (Melles Griot-35MAP431) with $200 \mathrm{~mW}$ and at $25^{\circ} \mathrm{C}$. First, the cells were cultured in a plate for 24 hours prior to addition of nanoparticles at concentration of $50 \mu \mathrm{g} / \mathrm{mL}$. After addition and incubation for further 24 hours, nonreacted nanoparticles were washed with PBS twice and fresh culture medium were added and each well was irradiated by the laser for 10 minutes. The efficiency of hyperthermia was then evaluated using MTT assay.

\section{Results}

Figure 2A shows the TEM images of nanocomposites synthesized by three different reducing agents where those prepared by $\mathrm{NaBH}_{4}$ (Figure 2a) are larger compared to those obtained by hydrazine sulfate (Figure 2b) and pre-synthesized AuNPs (Figure 2c). This is thought to be due to interaction of such nanoparticles with surface amine group of dendrimers hence forming a larger particles in the expense of smaller particles $[44,45]$. When hydrazine sulfate was used as a reducing agent, smaller particles with a homogeneous distribution was obtained which could be readily entrapped within the MDs cavity [46]. In order to evaluate the formation of folic, the UV-Vis spectra of the samples were recorded. Figure 2B indicates that all the IDA samples have a unique absorption peak in the range of 520-540 $\mathrm{nm}$ which reveals the formation of AuNPs. Plasmonic peak around $520 \mathrm{~nm}$ corresponds to the collective oscillation of gold free electrons [47]. During the synthesis reaction, the intensity of plasmon resonance peak was increased over time and the peak shifted toward higher wavelengths with respect to increase in particle size. Figure 2C shows the folic acid spectrum covering between 250-300 $\mathrm{nm}$ with a peak at $250 \mathrm{~nm}$. Figure 2D represents the results of IDAF samples where the peaks between $250-279 \mathrm{~nm}$ clearly confirms the presence of folic acid that is conjugated to IDA complex.

Generally, regardless of the functionalization techniques of MDs with gold, all nanostructure with free amine groups have the ability of exhibiting reactions with folic acids. In our recent report [48], we

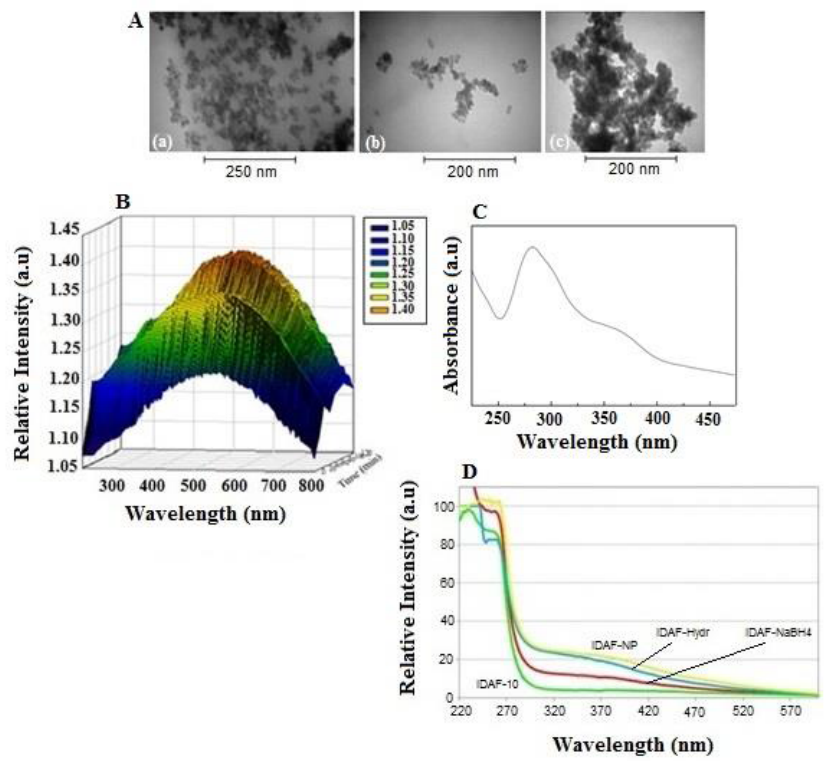

Figure 2: (A) TEM images of (a) IDAF-NaBH , (b) IDAF-Hydr, (c) IDAF-NP, UV-Vis absorption spectroscopy of (B) dendrimer-gold complex during the synthesis, (C) folic acid and (D) different IDAF nanocomposites. indicated that all samples have a unique absorption peak in the range of 520-540 nm which reveals the formation of AuNPs. However, other peaks at $280 \mathrm{~nm}$ and $320 \mathrm{~nm}$ also correspond to Au-NPs aggregation $[49,50]$. Recently, we reported that the absorption band between 320-370 $\mathrm{nm}$ indicates the formation of nanosized magnetite particles and the intensity of the light scattered depends on the polarizability and that in turn depends on the molecular weight [41]. In order to evaluate the presence of components in the resultant nanostructure, XRD analysis was performed. Figure 3 represents the XRD patterns containing diffraction peaks of magnetite, gold and folic acid at given angle $2 \theta$ for IDAF-NaBH 4 (Figure 3A) and IDAF-Hydr (Figure 3B) respectively. The crystallographic plane of (111), (200), (220) and (311) represent prove the FCC structure of gold (JCPDS No.00-04-0784). The number of diffraction lines in the case of IDAF-Hydr are more than IDAF- $\mathrm{NaBH}_{4}$ indicating that the majority of NPs are those synthesized using hydrazine sulfate reducing agent, which not only are smaller than

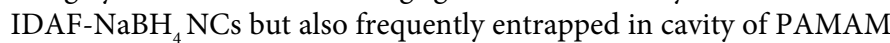
dendritic branches. Au-NPs could be calculated by using the Scherrer equation (Equation (1)) [51]. The calculation shows that the average particle size of Au-NPs obtained using $\mathrm{NaBH} 4$ reducing agent is about 4 orders larger than those formed by hydrazine sulfate.

$$
D=\frac{K \lambda}{\beta \cos \theta}
$$

Where, $D, \lambda$ and $\beta$ represent the mean diameter of particles, the wavelength of incident X-ray, and the full width at half height (FWHM) respectively and constant $K$ is equal to 0.9 .

The FTIR results for IDAF NCs are shown in Figure 4 where Figure $4 \mathrm{~A}$ illustrates the FTIR of folic acid for comparison. The peaks at 581 and $629 \mathrm{~cm}^{-1}$ depicted in Figure 4B represent the existence of iron oxide phase at all of synthesized structures. In the MD FTIR spectrum, amide band at 1570 and $1630 \mathrm{~cm}^{-1}$ represent the characteristics of PAMAM dendrimer. The AuNPs interact with amine terminated dendrimers stronger than carboxyl terminated dendrimers, since no change in half generations is revealed [52]. Type I amide band with the wavenumber of $1630 \mathrm{~cm}^{-1}$ ) is generally related to $\mathrm{C}=\mathrm{O}$ stretching vibration, which appertains to combination and structure of polymer backbone. Type II amide band with the wavenumber of $1571 \mathrm{~cm}^{-1}$ in $\mathrm{G} 3$ represents $\mathrm{N}-\mathrm{H}$ bending vibration $[53,54]$, which is eliminated during the gold and folic acid conjugation process while the band at $1630 \mathrm{~cm}^{-1}$ appeared without change. This shows that the gold nanoparticles interact with $\mathrm{N}-\mathrm{H}$ groups in magnetodendrimer structure whereas the polymer backbone relatively remains as its pure structure. The peaks at 155 and $1227 \mathrm{~cm}^{-1}$ corresponds respectively to $\mathrm{C}=\mathrm{C}$ and $\mathrm{C}-\mathrm{H}$ aromatic molecules of folic acid which confirm the molecules conjugation to nanodendrimer structure.

Figure 5 shows the thermal response of different synthesized NCs at $488 \mathrm{~nm}$ (Figure 5A) and $514 \mathrm{~nm}$ (Figure 5B) for 5 minutes. Clearly, the highest temperature rise was produced by $514 \mathrm{~nm}$ due to vicinity to SPR absorption peak at about $530 \mathrm{~nm}$. However, IDAF$\mathrm{NaBH}_{4}\left({ }^{*} 10\right)$ NCs exhibited higher temperature at $488 \mathrm{~nm}$, which is due to the fact that larger size of IDAF- $\mathrm{NaBH}_{4} \mathrm{NCs}$ because of larger AuNPs conjugated at the tip of PAMAM branches and the higher concentration of $\mathrm{HAuCl}_{4}$, have effectively caused an aggregation and clustering effect, hence leading to a blue Doppler shift (i.e., shorter wavelength) in the absorption.

The MTT results in Figure 6 indicates that all formulations of synthesized nanoparticles are biocompatible up to the concentration 
Citation: Khosroshahi ME, Tajabadi M (2017) Multifunctional Nanoplatform for Targeted Laser-induced Hyperthermia and Microscopy of Breast Cancer Cells using SPION-based Gold and Folic Acid Conjugated Nanodendrimers: An in vitro Assay. J Nanomed Nanotechnol 8: 432. doi: $10.4172 / 2157-7439.1000432$
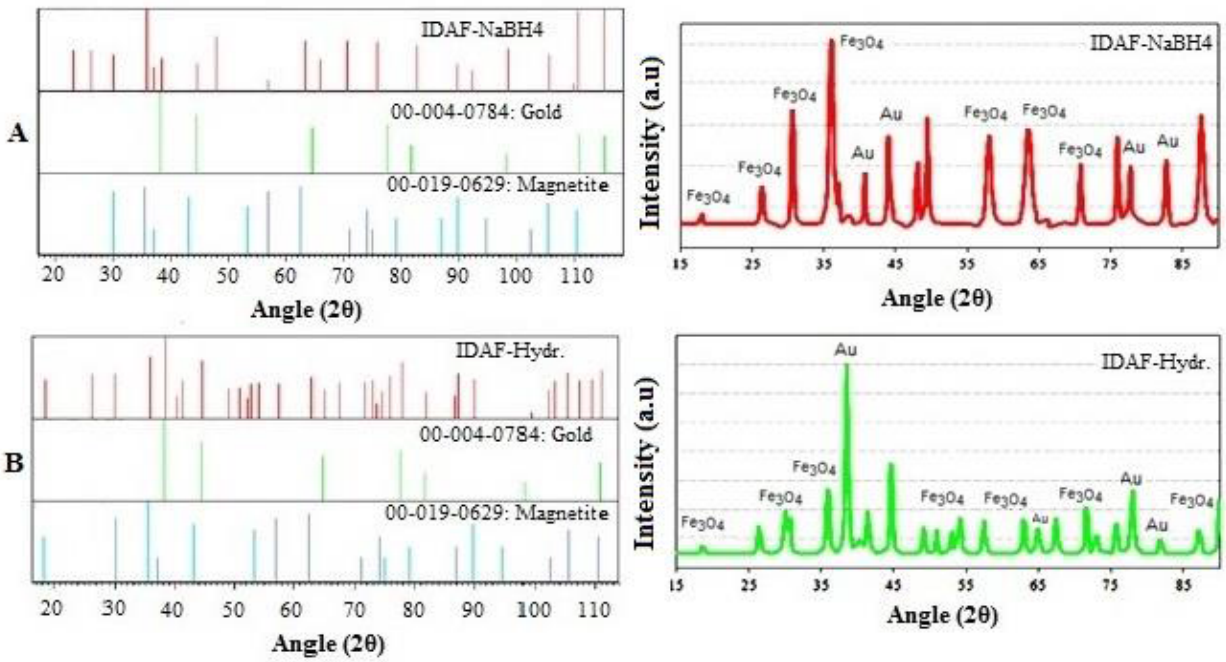

Figure 3: XRD patterns of (A) IDAF- $\mathrm{NaBH}_{4}$ and (B) IDAF- Hydr.
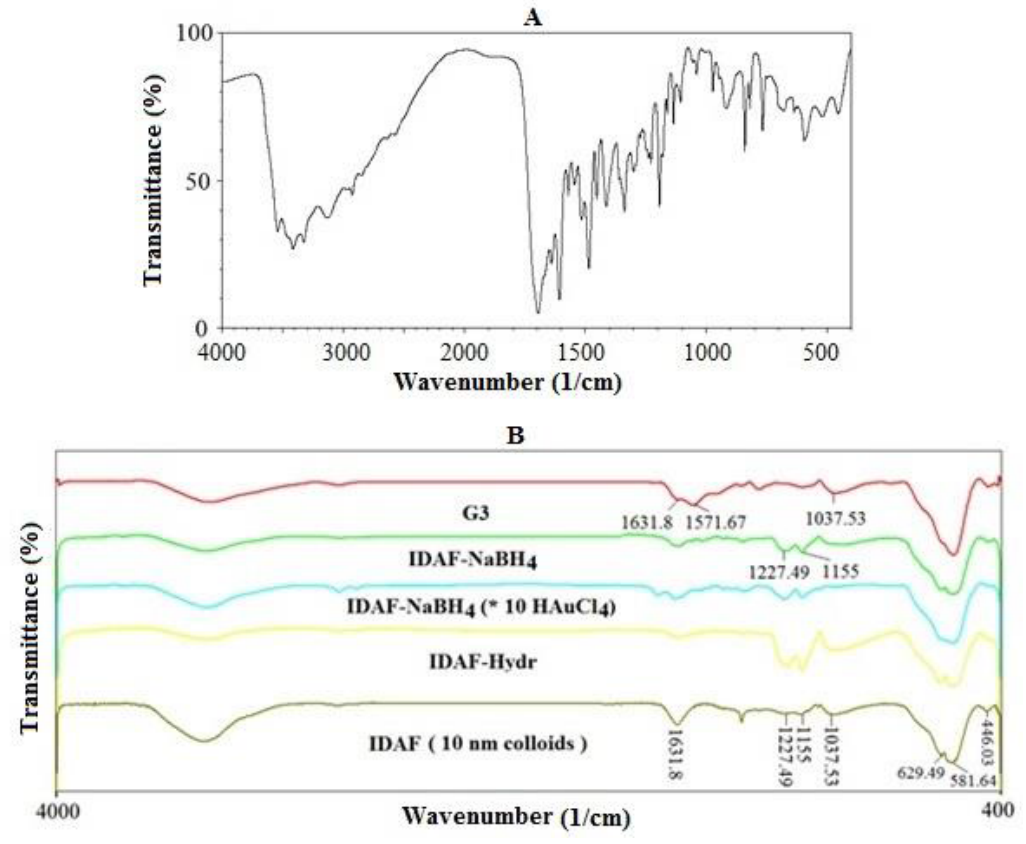

Figure 4: FTIR Spectra of (A) folic acid and (B) ID (G3) and other IDAF nanocomposites.

of about $50 \mu \mathrm{g} / \mathrm{mL}$ for the MDA MB 231(Figure $6 \mathrm{~A}$ ) and $25 \mu \mathrm{g} / \mathrm{mL}$ for the MCF 7 (Figure 6B) cell lines. By increasing the concentrations, the cell viabilities were gradually reduced which corresponds to less biocompatibility or higher cell death. The MDA MB 231 cells in contact with the nanoparticles showed a higher range of viability than MCF 7 cells, which could be explained by the presence of folate receptors on the surface of MDA MB 231 cells. One of major roles of AuNPs and folic acid is to prevent from possible electrostatic interaction between dendrimers with positive surface charge with the cells surface with negative charge, hence improving the biocompatibility of structure and consequently inhibiting significant NPs clustering.

In order to evaluate the uptake of IDAF formulations by cell lines, UV-Vis spectroscopy was used. Figures 7(A-D) and 7(G-J) demonstrate the nanoparticles uptake by MDA MB 231 and MCF 7 cell lines respectively. To prove the effect of folic acid on cell uptake, ID (G3) was used as a control group where SPION has an absorption band between $320-370 \mathrm{~nm}$ with three intense peaks at 350,360, and $370 \mathrm{~nm}$. Thus, the evaluation tests were performed at these wavelengths using UV-Vis spectroscopy. However, only the results of strongly up taken NCs by both cell lines and with relatively higher response at 350 $\mathrm{nm}$ are reported here (i.e., the nanoparticles uptake results shown at $360 \mathrm{~nm}$ and $370 \mathrm{~nm}$ are not reported). The results shown in Figure 7E represent the strong uptake of IDAF-Hydr and IDAF-10 NCs up to 180 and $100 \mu \mathrm{g} / \mathrm{mL}$ respectively by MDA MB 213 and about 10 and $9 \mu \mathrm{g} / \mathrm{mL}$ as loosely or weak uptake by the same cell lines (Figure 7F) 
Citation: Khosroshahi ME, Tajabadi M (2017) Multifunctional Nanoplatform for Targeted Laser-induced Hyperthermia and Microscopy of Breast Cancer Cells using SPION-based Gold and Folic Acid Conjugated Nanodendrimers: An in vitro Assay. J Nanomed Nanotechnol 8: 432. doi: $10.4172 / 2157-7439.1000432$
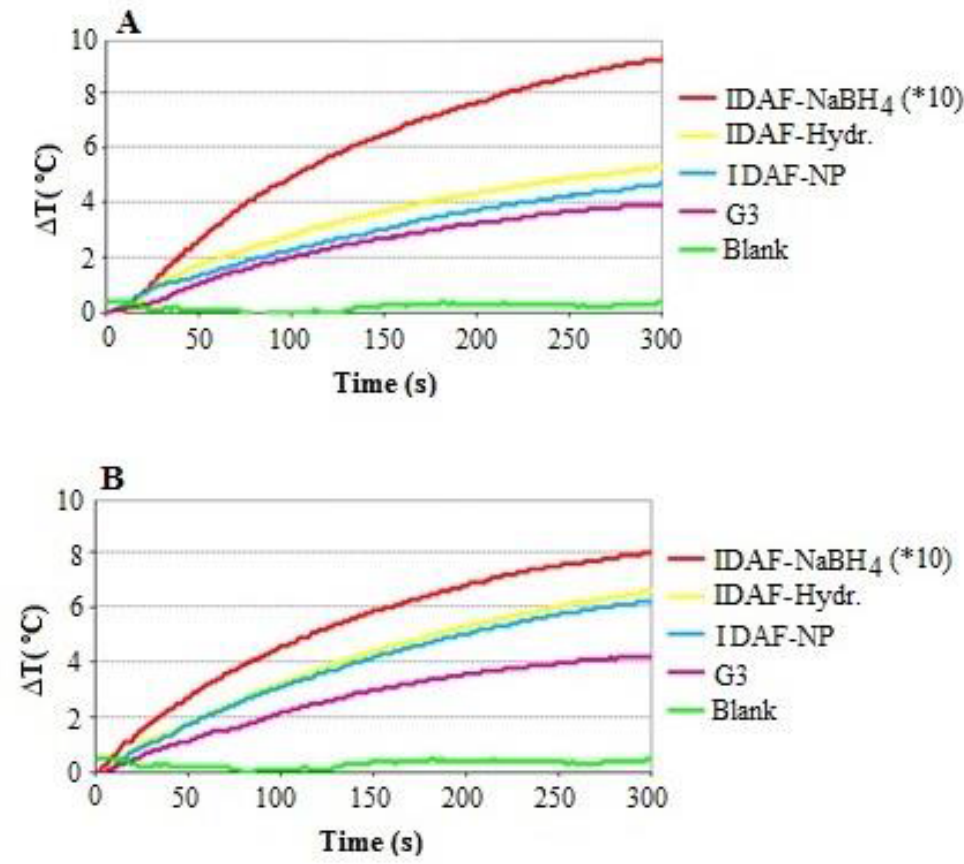

Figure 5: Thermal response of IDAF nanocomposites to argon laser irradiation at $488 \mathrm{~nm}$ and $514 \mathrm{~nm}$.
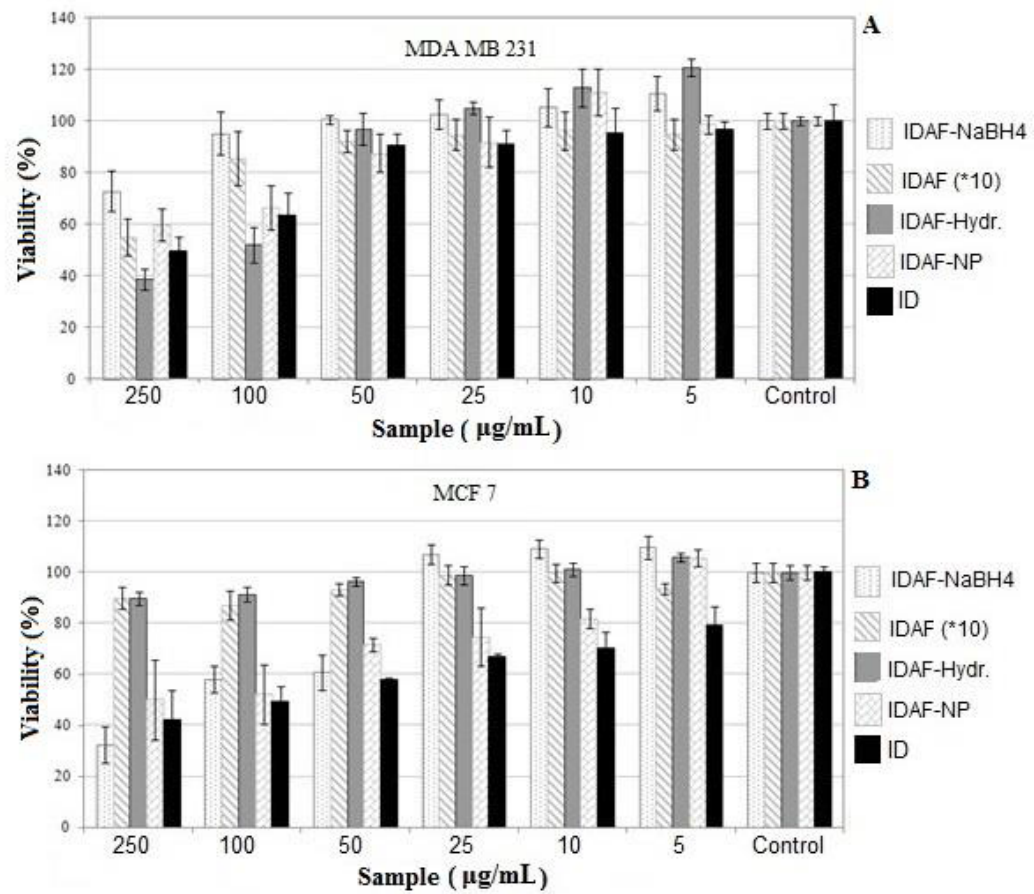

Figure 6: MTT assay of IDAF nanocomposites incubated with (A) MDA MB 231 and (B) MCF7 cell lines. Error bars are based on five samples.

i.e., those NCs which are weakly uptaken by the cells probably because of lack of conjugated folic acid. However, the unconjugated NCs can enter the cells by so called liquid-phase endocytosis, while those conjugated are strongly uptaken via endocytosis mechanism [55]. The difference between IDAF-Hydr and IDAF-10 NCs uptake can also be explained by the fact that smaller AuNPs are easily entrapped within the PAMAM branches, which effectively modify the complex structure and in turn reduce the nonspecific interactions at the surface of dendrimer and cell membrane. Similarly, in the case MCF 7 cell lines and for the same type of NCs, the strong uptakes are 160 and $140 \mu \mathrm{g} /$ $\mathrm{mL}$ (Figure $7 \mathrm{~K}$ ) and the weak uptakes are about 11 and $9 \mu \mathrm{g} / \mathrm{mL}$ (Figure 7I) respectively, no significant difference with the MDA MB 213 cells 
Citation: Khosroshahi ME, Tajabadi M (2017) Multifunctional Nanoplatform for Targeted Laser-induced Hyperthermia and Microscopy of Breast Cancer Cells using SPION-based Gold and Folic Acid Conjugated Nanodendrimers: An in vitro Assay. J Nanomed Nanotechnol 8: 432. doi: $10.4172 / 2157-7439.1000432$

Page 7 of 11

was observed. Generally, the uptake of NCs by MDA MB 231is higher than by MCF 7 cells due to presence of higher rate of folate receptors at the cell membrane.

The relative ratio of $\mathrm{Fe} / \mathrm{Au}$ present in all IDAF samples is given in Figure 8A where IDAF-Hydr and IDAF-NCs represent the lowest and highest $\mathrm{Fe}$ content respectively i.e., the use of hydrazine sulfate as a reducing agent has produced lower Fe:Au ratio i.e., higher rate of AuNP loading, which are likely entrapped within the dendrimer cavities. Figure $8 \mathrm{~B}$ shows the SEM micrographs of nanoparticle in close contact with breast cancer cells. As it can be seen in Figure 8B,
G3 nanoparticles with no targeting moiety have largely attached to the surface of the cells. On the other hand, folic acid functionalized NCs have mostly interacted with folate receptors of the cell surface and actively entered the cell cytoplasm, which implies they could not be observed in the SEM micrographs and Fe map patterns [56]. In order to quantitatively appraise attachment of AuNPs to MD, WDX (Wavelength-dispersive X-ray spectroscopy) analysis was performed. The analysis of distribution map of Fe element confirms the presence of gold phase in the prepared nanoparticles (Figure 8C) [57]. The map distributions confirm that IDAF-Hydr and IDAF-10 NC have highest gold content. Figure 8D shows the fluorescence images of the MDA MB
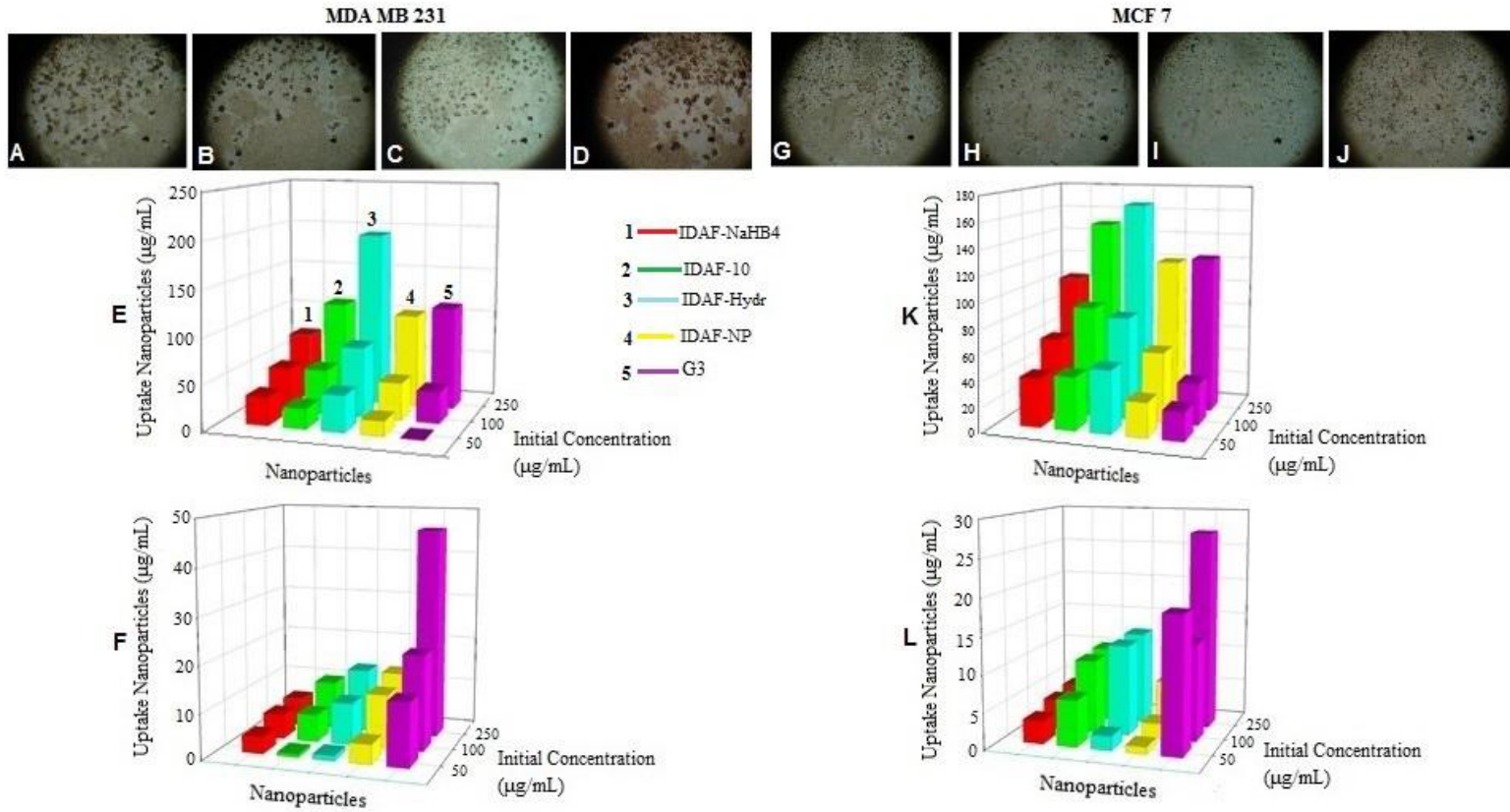

Figure 7: Optical microscope images of MDA MB 231 cell lines with (A) IDAF-NaBH, (B) IDAF-10, (C) IDAF-Hydr and (D) IDAF-NP, with corresponding strong $(E)$ and weak $(F)$ up take of IDAF NCs. Similarly for MCF 7 cell lines with (G) IDAF-NaBH ${ }_{4}$, (H) IDAF-10, (I) IDAF-Hydr and (J) IDAF-NP with corresponding strong $(\mathrm{K})$ and weak $(\mathrm{L})$ up take of IDAF NCs.

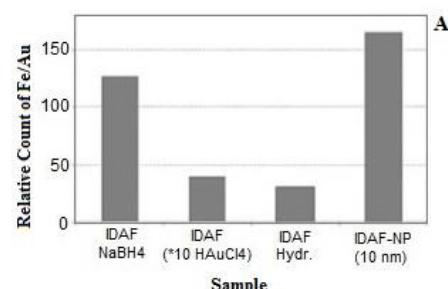

Sample
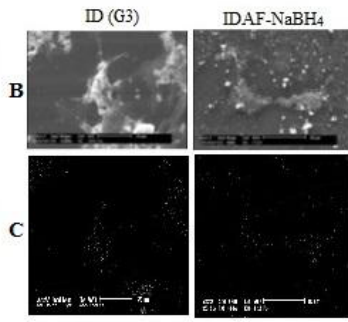

$\stackrel{50 \mu \mathrm{m}}{\longrightarrow}$

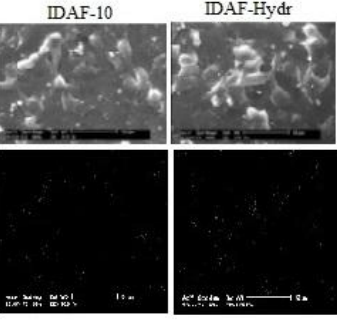

(in)

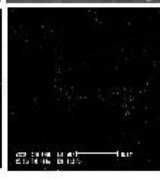

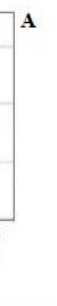

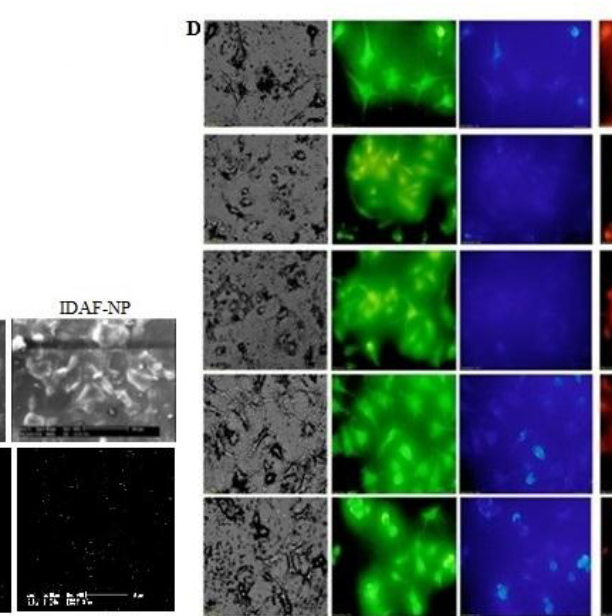

Magnification $* 10$

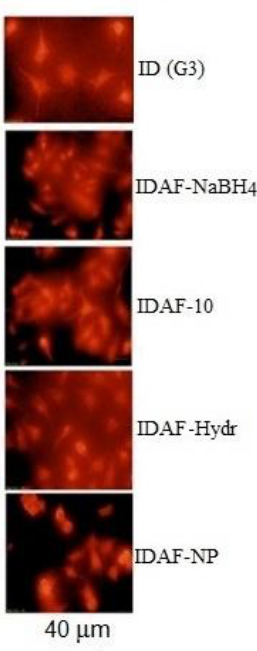

$40 \mu \mathrm{m}$

Figure 8: (A) Relative counts of Fe/Au for different synthesized IDAF NCs, (B) the SEM images of MDA MB 231 cell lines and (C) Wavelength-dispersive X-ray spectroscopy-WDX of corresponding Fe scattering map and (D) Fluorescence microscope images of IDAF NCs uptake by MDA MB cell lines excited at different wavelengths using Blue, Green and Red filters respectively. 
Citation: Khosroshahi ME, Tajabadi M (2017) Multifunctional Nanoplatform for Targeted Laser-induced Hyperthermia and Microscopy of Breast Cancer Cells using SPION-based Gold and Folic Acid Conjugated Nanodendrimers: An in vitro Assay. J Nanomed Nanotechnol 8: 432. doi: $10.4172 / 2157-7439.1000432$

Page 8 of 11

231 cell lines after IDAF NCs uptake using blue, green and red filters of fluorescence microscope. These results indicate that all formulations are highly efficient in fluorescent labeling of breast cancer cells and are in good agreement with other researches who also confirmed the fluorescent property of dendrimer/folic acid nanoparticles [57,58]. It has been shown that after addition of $\mathrm{HAuCl}_{4}$ to structure, the fluorescence intensity is red shifted towards the longer wavelength [59]. After adding the reducing agent, the peaks are changed considerably which shows the attachment of AuNPs to the dendrimers. The shift of fluorescence spectra could be explained by strong interaction between gold crystals and amine groups of dendrimer [57].

Based on the fact that MDA MB 231 cells have higher number of folate receptors and the results of Figure 7E, IDAF-Hydr and IDAF-10 NCs were selected for laser hyperthermia experiment. Exposure of the NCs to laser radiation produces heat described by Eq. (3), followed by heat depletion to the cells and surrounding environment via thermal conduction. It is assumed that the total absorbed energy of NCs is transferred to the surrounding medium. Figure 9A and 9B indicates respectively, the MDA MB 231 cells as control group before and after laser irradiation, Figure 9C-9E represents MDA MB 231 cells with IDAF-10 NCs before and after irradiation, and similarly, Figure 9F-9H shows the MDA MB 231 cells with IDAF-Hydr NCs. The morphology and spreading of cells is clearly seen in all samples. Figure 9I indicates IDAF-Hydr NC with least cancer viability of about $65 \%$ after laser exposure.

\section{Discussion}

In this study, a multifunctional SPION-based nanodendrimer with capability of magnetic guidance conjugated by folic acid for targeting and AuNPs for photothermal purpose was designed and invitro tests were performed. In the absence of phase transformations, the temperature distribution around optically-stimulated plasmonic nanoparticles (i.e., heat source) placed in a surrounding medium is normally described by the parabolic Fourier's heat conduction equation.

$$
\rho_{g}(r) c_{g}(r) \frac{\partial T(r, t)}{\partial t}=K_{m} \nabla^{2} T(r, t)+Q_{s}(r, t)
$$

where $T(r, t)(\mathrm{K})$ is local temperature, $Q_{\mathrm{s}}\left(\mathrm{W} / \mathrm{m}^{3}\right)$ is the heating source $\rho_{g}(r)\left(\mathrm{Kg} / \mathrm{m}^{3}\right)$, and $c_{g}(r)(\mathrm{J} / \mathrm{Kg} \mathrm{K})$, are density, and specific heat of a AuNP, respectively, $K_{m}^{g}$ is the thermal conductivity of the surrounding medium $(\mathrm{W} / \mathrm{mK})$, and $r$ is the radius distance $(\mathrm{m})$ from the heated nanoparticles For a single AuNP exposed to a laser beam the power of heat generation is

$$
P=I \sigma_{\alpha}
$$

where $\sigma_{\alpha}$ and $I$ are absorption cross-section and the intensity respectively. Also, $Q_{g}=P / V_{g}$ where $V_{g}$ is the volume of the NP. To calculate $Q_{g}(r, t)$, it is assumed that the size of a NP is smaller than the laser wavelength so that electrons inside the NPs respond collectively to the applied electric field $E$ of the laser radiation, [21]

$$
Q_{g}(r, t)=<j(r, t) \cdot E(r, t)>
$$

where $E(r, t)=\operatorname{Re}\left[E(r) \cdot e^{-i \omega t}\right]$. In the steady-state, the local temperature around a single NP is described by

$$
\Delta T(r)=\frac{V_{g} Q_{g}}{4 \pi K_{m} R_{g}}
$$

where $\mathrm{R}_{\mathrm{g}}$ is the radius of AuNP. The $\mathrm{Eq}$ (7) is valid outside the NP, i.e., $r>R_{g}$. It can be shown that when $\lambda>>R_{g}$, the maximum temperature increase occurs at $r=R_{g}[60]$

$$
\Delta T_{\max }\left(I_{0}\right)=\frac{R_{g}^{2}}{3 K_{m}} \frac{\omega}{8 \pi}\left|\frac{3 \varepsilon_{m}}{\varepsilon_{g}+2 \varepsilon_{m}}\right|^{2} \operatorname{Im} \varepsilon_{\mathrm{g}} \frac{8 \pi \cdot I_{0}}{c \sqrt{\varepsilon_{m}}}
$$

Equation (8) shows that temperature of the medium containing plasmonic nanoparticles is proportional to the square of the nanoparticle radius, i.e. $\Delta T \propto R_{g}^{2}$ and that the size dependence of

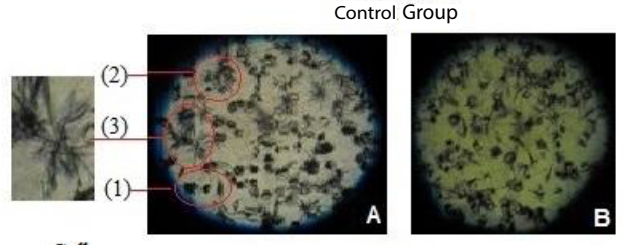

Cell

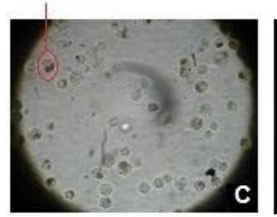

IDAF-10

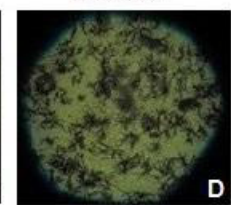

IDAF-Hydr
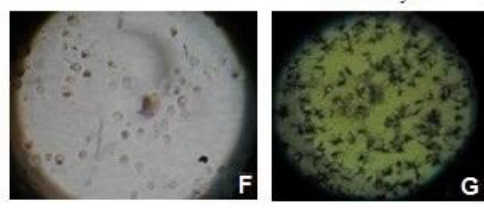
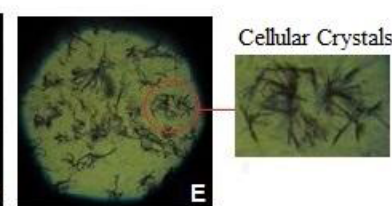
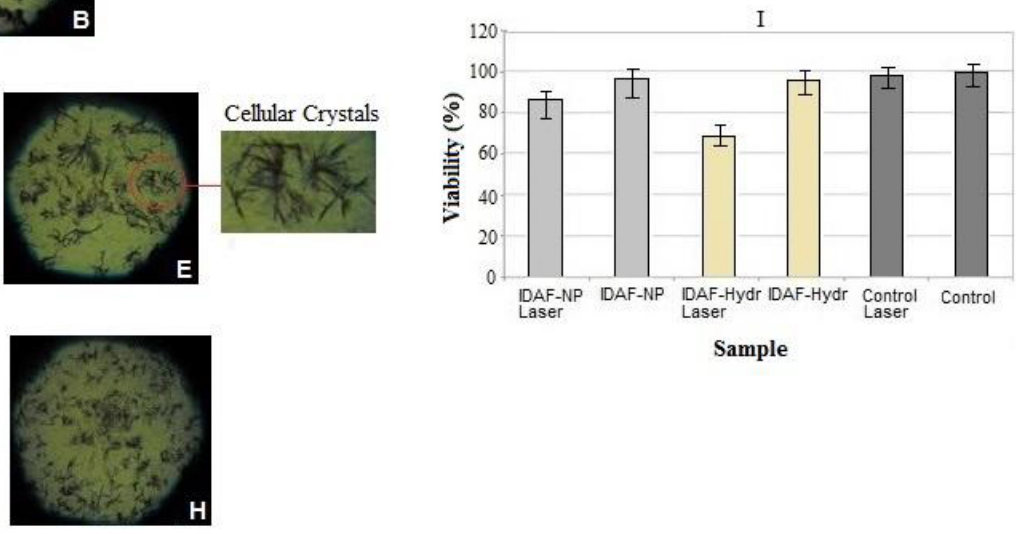

Figure 9: Optical microscope images of MDA MB 231 cell lines containing (A) ID (G3) as control group before laser irradiation, (B) after irradiation, (C,D) IDAF-10 before and $(E)$ after irradiation, $(F, G)$ IDAF-Hydr before and $(H)$ after irradiation. The viability evaluation after laser treatment is shown in (I) where IDAF-Hydr has the lowest viability i.e., highest death rate of cells. Note the cells crystallization after laser exposure due to dehydration. 
Citation: Khosroshahi ME, Tajabadi M (2017) Multifunctional Nanoplatform for Targeted Laser-induced Hyperthermia and Microscopy of Breast Cancer Cells using SPION-based Gold and Folic Acid Conjugated Nanodendrimers: An in vitro Assay. J Nanomed Nanotechnol 8: 432. doi: $10.4172 / 2157-7439.1000432$

Page 9 of 11

the temperature increase is mainly governed by the total rate of heat generation and by heat transfer through the NP surface. As the TEM results show, the use of $\mathrm{NaBH}_{4}$ as a reducing agent produced clusters of Au-NPs with larger particle size than the other formulation. Based on above analysis (Eq. 8) we expect to obtain a higher temperature with IDAF-NaBH 4 as it is shown in Figure 5.

The $\mathrm{NH}_{2}$ groups on the surface of dendrimers electrostatically interact with the cell surface and form clusters of nanoparticles which may be harmful to cells [61-63]. It has been reported that surface modification of dendrimers by e.g., AuNP and folic acid molecules may improve their biocompatibility $[64,65]$. The decrease in cell viability with increase of nanoparticle concentration in the medium is more likely due to the enhanced uptake and the surface coverage of cells as a result of interaction between the cationic periphery of PAMAM-grafted magnetite nanoparticles and negatively charged cell surfaces [66]. The mechanism of nanoparticle uptake by cells is considered a twostep process: i) binding of nanoparticles to the cell surface, followed by ii) the internalization of nanoparticles by the specific endocytosis pathway. The relative Zeta potential $\mathrm{Z}_{\mathrm{r}}$ of cells during the adsorption of nanoparticles is expressed as:

$$
Z_{r}=\exp \left(m_{\text {bin }} \times \frac{\beta_{\text {binding }}}{2}+m_{\text {int }} \times \frac{\beta_{\text {int }}}{2}\right)
$$

Where $m_{\text {binding }}$ is the total mass of nanoparticles binding to the cell surface, $\mathrm{m}_{\mathrm{int}}$ is the total mass of nanoparticles internalized within the cell and $\beta$ measures how the presence of nanoparticle adsorption affect the free energy of the ions at a distance from the cell surface. Thus, when nanoparticles bind onto the negatively charged cell surface with the same sign of $\xi$, it increases the free energy of the ions at a distance from the cell surface, so the $\beta$ binding is positive i.e., $Z_{\mathrm{r}}>1$. However, in our case, IDAF NCs have positively charged $\xi$, which is opposite to $\xi$ sign of the cells. Therefore, the free energy of the ions at a distance from the cell surface is decreased and $\beta$ binding is negative i.e., $Z_{r}<1$ and the internalization mechanism dominates. The binding and internalization processes could be modeled by Langmuir adsorption [62,63]. Thus, the over expression of MDA MB 231 cells enhances the internalization process compared to MCF 7 cells.

AuNPs have an effective influence on the fluorescence spectra of dendrimer $[45,67]$ due to the internal interaction between flexible structure of dendrimer and rigid structure of entrapped AuNPs, whereas the larger particles damp the fluorescence of dendrimers. These phenomena could be explained in terms of fluorescence resonance energy transfer (FRET) [67]. In most cases, the fluorescence spectra of IDAF-Hydr are stronger than others more likely due to smaller size of AuNPs which renders their easier entrapment by dendrimers and hence intensify the fluorescence signals. Recently, we reported that the corresponding fluorescence emission covers a range between (490-550) $\mathrm{nm}$ with a significant bandwidth between $480-500 \mathrm{~nm}$ where $450 \mathrm{~nm}$ peak is assigned to carbocyclic acid and $470 \mathrm{~nm}$ to $-\mathrm{NH}_{2}$ bond [53] Three pronounced emitted peaks were observed at 488,495 and 550 $\mathrm{nm}$. The changes in molecular conformation of higher dendrimer generations favor a $\pi-\pi$ interaction between phenyl rings, which leads to the formation of phenyl excimer.

The SPR-induced heat production is influenced by the uptake of NCs by the cells and thus their absorbance. The absorbance for IDAFHydr and IDAF-10 NCs uptak by MDA MB 231 cells were obtained as 0.3466 and 0.2681 , respectively. As a result, it can be deduced that $54.98 \%$ of initial laser power is used to produce local heat for IDAFHydr NPs compared to IDAF- 10 NCs with $46.06 \%$. Some of the attached cells spread radially from the center and developed filopodia (point 1) Figure 9A. Consequently, filopodia have an important role in e.g., cell migration. The initiation and elongation of filopodia depend on the precisely regulated polymerization, convergence and crosslinking of actin filaments. The surface of cells not yet spread, were convoluted in to microridges (point 2). Neighboring cells maintained physical contact with one another through multiple extensions (point 3). A common effect observed throughout the laser irradiation experiment was the formation of cellular crystallization, which can occur via either (i) dehydration, (ii) freezing. In our case, water is vaporized from the cells due to laser-induced dehydration, hence leading to a supersaturated solution and mineral such as sugar or salt which precipitate inside their cells. It is important to note that in dehydration process, the crystals that are formed can puncture the cell membrane causing the cell to burst (i.e., a mechanical type of hemolysis) hence leading to cell death. Figure 9B indicates the results of viability test for IDAF-NCs after laser treatment. As it is seen, IDAF-Hydr has caused a higher rate of cell death, which is explained by the fact that this formulation with smaller entrapped AuNPs has acted as comparatively stronger heat generating source. These findings are in good agreement with other similar results $[68,69]$.

\section{Conclusion}

This work provides information concerning the synthesis of the inorganic-organic hybrid composite consisted of magnetite nanoparticle, dendrimer, AuNP and folic acid molecules. The results indicate an enhanced efficiency of loading AuNPs using hydrazine sulfate as a reducing agent. The WDX and TEM results suggest that the use of hydrazine sulfate as a reducing agent can both produce a uniform structure and load higher degree of Au-NPs in the materials. The interaction of $488 \mathrm{~nm}$ and $514 \mathrm{~nm}$ wavelengths with the all nanocomposite media resulted in temperature increase with IDA$\mathrm{NaBH} 4$ and IDA-Hydr. The fluorescent property of MDs was studied by fluorescent microscopy and the thermal response of different IDAF NCs were recorded. The cytotoxicity of these NCs was analyzed by MTT. Photothermal hyperthermia was performed using MDA MB 231 breast cancer cell lines due to their higher folate receptor expression. Based on these analysis, we believe that IDAF-Hydr NCs potentially is a suitable candidate and superior to other IDAF NCs for bioimaging and photothermal therapy of cancer cells due to their higher fluorescence efficiency and lower cancer cells viability (i.e., higher cell death).

\section{Acknowledgment}

Prof. MEK and Dr MT would like to acknowledge the consultancy of Dr Sh Bonakdar and V. Asgari from National Cell Bank of Pasteur Institute of Iran who also kindly provided the cells for the research.

\section{References}

1. Luqmani $Y$ (2008) Mechanisms of drug resistance in cancer chemotherapy Med Princ Pract 14: 35-48.

2. Kaasgaard $T$, Andersen $T$ (2010) Liposomal cancer therapy: exploiting tumor characteristics. Expert Opin Drug Del 7: 225-243.

3. Urban C, Urban A, Charron H, Joshi A (2013) Externally modulated theranostic nanoparticles. Tranl Cancer Res 2: 292-308.

4. Chen F, Ehlerding E, Cai W (2014) Theranostic nanoparticles. J Nucl Med 55 1919-1922.

5. Pankhurst Q, Connolly J, Jones S. Dobson, J (2003) Applications of magnetic nanoparticles in biomedicine. J Phys D: Appl Phys 36: 167-181.

6. Gupta A, Gupta M (2005) Synthesis and surface engineering of iron-oxide nanoparticles for biomedical applications. Biomaterials 26: 3995-4021.

7. Jiang Q, Lang X (2007) Size dependence of structures and properties of materials. Open Nanosci J 1: 32-59. 
Citation: Khosroshahi ME, Tajabadi M (2017) Multifunctional Nanoplatform for Targeted Laser-induced Hyperthermia and Microscopy of Breast Cancer Cells using SPION-based Gold and Folic Acid Conjugated Nanodendrimers: An in vitro Assay. J Nanomed Nanotechnol 8: 432. doi: $10.4172 / 2157-7439.1000432$

8. Khosroshahi ME, Ghazanfari L (2010) Preparation and characterization of silica-coated iron-oxide bionanoparticles under N2 gas. Physica E 42: 1824-1829.

9. Thomas S, Park I, Jeong Y (2013) Magnetic iron oxide nanoparticles for multimodal imaging and therapy of cancer. Int J Mol Sci 14: 15910-15930.

10. Estelrich J, Escribano E, Queralt J (2015) Iron oxide nanoparticles for magnetically-guided and magnetically-responsive drug delivery. Int $\mathrm{J}$ Mol Sci 16: 8070-8101

11. Tomalia DA (2005) Birth of a new macromolecular architecture: dendrimers as quantized building blocks for nanoscale synthetic polymer chemistry. Prog Polym Sci 30: 294-324.

12. Peng X, Pan Q, Rempel G (2008) Bimetallic dendrimer-encapsulated nanoparticles as catalysts: a review of the research advances. Chem Soc Rev 37: 1619-1628.

13. Yang W, Pan C (2009) Synthesis and Fluorescent properties of biodegradable hyperbranched poly (amido amine). Macromol Rapid Commun 30: 2096-2101.

14. Ciolkonwaski M, Petersen J (2012) Surface modification of PAMAM improves its biocompatibility. Nanomedicine: Nanotech Biol Med 12: 815-817.

15. Okugaichi A, Torigoe K, Yoshimura T, Esumi K (2006) Interaction of cationic gold Nanoparticles and carboxylate-terminated poly (Amidoamine) dendrimers. Colloids and Surfaces A: Physicochem Eng Aspects 273: 154-160.

16. Balogh L, Valluzzi R, Laverdure K, Gido S, Hagnauer G, et al. (1999) Formation of silver and gold dendrimer nanocomposites. J Nanoparticle Res 1: 353-368.

17. Esumi K, Houdatsu H, Yoshimur T (2004) Antioxidant action by gold-PAMAM dendrimer nanocomposites. Langmuir 20: 2536-2538.

18. He J, Valluzzi R, Yang K, Olukhanyan T, Sung C, et al. (1999) Electrostatic multilayer deposition of a gold-dendrimer nanocomposite. Chem of Mater 11 3268-3274.

19. Pustovalov VK, Babenkov V (2004) Optical properties of gold nanoparticles at laser radiation wavelengths for laser applications in nanotechnology and medicine. Laser Phys Lett 10: 516-520.

20. Khosroshahi ME, Ghazanfari L (2012) Physicochemical characterization of $\mathrm{Fe}_{3} \mathrm{O}_{4} / \mathrm{SiO}_{2} / \mathrm{Au}$ multilayer nanostructure. Mater Chem Phys 133: 55-62.

21. Baffou G, Quidant R (2013) Thermo-plasmonics: using metallic nanostructures as nano-sources of heat. Laser Photonics Rev 7: 171-187.

22. Hasannejad Z, Khosroshahi ME (2013) Synthesis and evaluation of time dependent properties of plasmonic-magnetic nanoparticles. Opt Mat 35: 644651.

23. Ghazanfari L, Khosroshahi ME (2014) Simulation and experimental results of optical and thermal modeling of gold nanoshells. Mat Sci Eng C 42: 185-191.

24. Khlebtsov B, Zharov V, Melikov A, Tuchin V, Khlebtsov N (2006) Optical amplification of photothermal therapy with gold nanoparticles and nanoshells. Nanotechology 17: 5167-5179.

25. Huang X, Jain P, El-Sayed IH, El-Sayed MA (2007) Gold nanoparticles Interesting optical properties and recent applications in cancer diagnostics and therapy. Nanomed 2: 681-693.

26. Luke G, Eager D, Emelianov SY (2011) Biomedical applications of photoacoustic imaging with exogenous contrast agents. Annl Biomed Eng 40: 422-437.

27. Khosroshahi ME, Mandelis A, Lashkari B (2015) Frequency-domain photothermo-acoustic and ultrasonic imaging of blood and opto-thermal effects of plasmonic nanoparticle concentrations. J Biomed Opt 20: 076009

28. Pattani V, Tunnell J (2012) Nanoparticle-mediated photothermal therapy: A comparative study of heating for different particle types. Lasers Surg Med 44: $675-684$

29. Khosroshahi ME, Hassannejad Z, Firouzi M, Arshi A (2015) Nanoshellmediated targeted photothermal therapy of HER2 human breast cancer cells using pulsed and continuous wave lasers: an in vitro study. Lasers Med Sci 30: 1913-1922.

30. Khandhar A, Ferguson R, Krishnan K (2011) Monodispersed nanoparticles optimized for magnetic fluid hyperthermia:implications in biological systems. $J$ Appl Phys 109: 07B310-07B313.

31. Skrabalak S, Chen J, Au L, Lu X, Li X, et al. (2007) Gold Nanocages for biomedical applications. Adv Mater 19: 3177-3184.
32. Park S, Lee J, Bae S, Kang B (2015) Comparative hyperthermia effects of silica-gold nanoshells with different surface coverage of gold clusters on epithelial tumor cells. Int J Nanomed 10: 261-271.

33. Liao Sh, Liu Ch, Bastaoti B, Suzuki N (2015) Functionalized magnetic iron oxide/alginate core-shell nanoparticles foe targeting hyperthermia. Int $J$ Nanomed 10: 3315-3328.

34. Sadat M, Patel R, Sookoor J, Budko S, Ewing RC (2014) Effect of spatial confinement of magnetic hyperthermia via dipolar interactions in $\mathrm{Fe} 3 \mathrm{O} 4$ nanoparticles for biomedical applications. Mat Sci Eng C 42: 52-63.

35. Boubeta C, Simeoniides, Marridis A, Angeakeris M, Iglesias O, et al. (2013) Learning from nature to improve the heat generation of iron-oxide nanoparticles for magnetic hyperthermia applications. Sci Rep 3: 1-7.

36. Khosroshahi ME, Ghazanfari L Hasannejad Z, Lenherd S (2015) In-Vitro application of doxorubicin loaded magnetoplasmonic thermosensitive liposomes for laser hyperthermia and chemotherapy of breast cancer. $J$ Nanomed Nanotech 6: 1000298.

37. Weitman S, Lark R, Cone L, Fort D, Frasca V (1992) Distribution of the folate receptor GP38 in normal and malignant cell lines and tissues. Cancer Res 52 396-3401.

38. Ross J, Chauduri PK, Ratnam M (1994) Differential regulation of folate receptor isoforms in normal and malignant tissues in-vivo and in established cell lines: Physiologic and clinical implications. Cancer 73: 2432-2443.

39. Khosroshahi ME, Tajabadi M (2016) Characterization and cellular fluorescence microscopy of superparamagnetic nanoparticles functionalized with third generation nanomolecular dendrimers: In-Vitro cytotoxicity and uptake study. J Nanomater Mol Nanotechnol 5: 1-11.

40. Tajabadi M, Khosroshahi ME (2012) Effect of alkaline media concentration and Modification of temperature on magnetite synthesis method using $\mathrm{FeSO}_{4}$ $\mathrm{NH}_{4} \mathrm{OH}$. Int J Chem Eng Appl 3: 206-211.

41. Tajabadi M, Khosroshahi ME (2013) An efficient method of synthesis coated with third generation PAMAM dendrimer. Colloids Surf A: Physiochem. Eng Aspects 431: 18-26.

42. Ghandoor H, Zidan H, Khali M, Ismail M (2007) Synthesis and Some Physical Properties of Magnetite (Fe3O4) Nanoparticles. Int J Electrochem Sci 7: 5734 5745

43. Shauo Ch, Chao Ch, Wu T, Shy H (2007) Magnetic and optical properties of isolated magnetic nanocrystals. Mat Tran 48: 1143-1148.

44. Shi X, Ganser TR, Kai S, Balogh LP, James R (2006) Characterization of crystalline dendrimer-stabilized gold nanoparticles. Nanotechnology 17: 10721078.

45. Jiang G, Wang $Y$, Sun $X$ (2010) Influence on fluorescence properties of hyperbranched poly(amidoamine)s by nano golds. J Polym Sci: Part B: Polym Phys 48: 2386-2391.

46. Torigoe K, Suzuki A, Esumi K (2001) Au(III)-PAMAM interaction and formation of Au-PAMAM nanocomposites in ethyl acetate. J Colloid and Interf Sci 241 346-356.

47. Shi X, Ganser T, Sun K, Baker J (2006) Characterization of crystalline dendrimer-stabilized gold nanoparticles. Nanotechnology 17: 1072-1078.

48. Tajabadi M, Khosroshahi ME, Bonakdar Sh (2015) Imaging and therapeutic applications of optical and thermal response of SPION-based third generation plasmonic nanodendrimers. Optics Photonics J 5: 212-226.

49. Mosseri S, Henglein A, Janata E (1989) Reduction of dicyanoaurate (I) in aqueoussolution:formation of nonmetallic clusters and colloidal gold. J Physical Chem 93: 6791-6795.

50. Divsar F, Nomani A, Chaloosi M, Haririan I (2009) Synthesis and characterization of gold nanocomposites with modified and intact polyamidoamine dendrimers. Microchimica Acta 165: 421-426.

51. Faiyas A, Vinod E, Joseph J, Ganesan R, Pandey R (2009) Dependence of pH and surfactant effect in the synthesis of magnetite (Fe3O4) nanoparticles and its properties. J Mag and Mag Mat 322: 400-404.

52. Esumi K, Suzuki A, Yamahira A, Torigoe K (2000) Role of poly (Amidoamine) dendrimers For preparing nanoparticles of gold, platinum, and silver. Langmuir 16: $2604-2608$ 
Citation: Khosroshahi ME, Tajabadi M (2017) Multifunctional Nanoplatform for Targeted Laser-induced Hyperthermia and Microscopy of Breast Cancer Cells using SPION-based Gold and Folic Acid Conjugated Nanodendrimers: An in vitro Assay. J Nanomed Nanotechnol 8: 432. doi: $10.4172 / 2157-7439.1000432$

Page 11 of 11

53. Grabchev I, Bojinov V, Chovelon J (2003) Synthesis, photophysical and photochemical properties of fluorescent poly (Amidoamine) dendrimers. Polymer 44: 4421-4428.

54. Baykal A, Toprak M, Durmus Z, Senel M, Sozeri H (2012) Synthesis and characterization of dendrimer-encapsulated iron and iron-oxide nanoparticles. J Superconductivity and Novel Magnetism 25: 1541-1549.

55. Pradhan P, Giri J, Banerjee R, Bellare J, Bahadur D (2007) Cellular interactions of lauric acid and dextran-coated magnetite nanoparticles. J Mag and Mag Mat 311: $282-287$.

56. Sonvico F (2005) Folate-conjugated iron oxide nanoparticles for solid tumor targeting as Potential specific magnetic hyperthermia mediators: synthesis. physicochemical characterization and in-vitro experiments. Bioconjugate chemistry 16: 1181-1188.

57. Landmark K, DiMaggio S, Ward J, Kelly C, Vogt S, et al. (2008) Synthesis, characterization, and in-vitro testing of superparamagnetic iron oxide nanoparticles using folic acid-conjugated dendrimers. ACS Nano 2: 773-783.

58. Shi X (2009) Multifunctional dendrimer-modified multiwalled carbon nanotubes: synthesis, characterization and in-vitro cancer cell targeting and imaging. Biomacromolecules 10: 1744-1750.

59. Stemmler M, Stefani F, Bernhardt S, Bauer R (2009) One-pot preparation of dendrimer-gold nanoparticle hybrids in a dipolar aprotic solvent. Langmuir 25 : $12425-12428$.

60. Govorov A, Richardson H (2007) generating heat with metal nanoparticles. Nanotoday 2: 30-38.
61. Biswal BK (2009) Tumor cell imaging using the intrinsic emission from PAMAM dendrimer: a case study with HeLa cells. Cytotechnology 61: 17-24.

62. Roberts J, Bhalgat M, Zera R (1996) Preliminary biological evaluation of polyamide oamine (PAMAM) Starburst dendrimers. J of Biomed Mat Res 30: 53-65.

63. Malik N, Wiwattanapatapee R, Klopsch R, Lorenz K, Frey H, et al. (2000) Dendrimers: relation-ship between structure and biocompatibility in vitro, and preliminary studies on the biodistribution of 125 I-labelled polyamidoamine dendrimers in-vivo. J contr. Release 65: 133-148.

64. Nam H (2009) Biodegradable PAMAM ester for enhanced transfection efficiency with low cytotoxicity. Biomaterials 30: 665-673.

65. Jevprasesphant R, Penny J, Jalal R, Attwood D, McKeown NB, et al. (2003) The influence of surface modification on the cytotoxicity of PAMAM dendrimers. Int J Pharmaceutics 252: 263-266.

66. Pradhan P, Giri J, Rieken F, Koch C, Mykhaylyk O, et al. (2010) Targeted temperature sensitive magnetic liposomes for thermochemotherapy. J Cont Release 142: 108-121.

67. Zhang Z, Rong F, Niu S, Xie Y, Wang Y, et al. (2010) Investigation the Effects of Nano golds on the fluorescence properties of the sectorial poly (amidoamine) (PAMAM) dendrimers. Appl Surf Sci 56: 7194-7199.

68. El-Sayed IH, Huang X, El-Sayed M (2006) Selective laser photo-thermal therapy of epithelia carcinoma using anti-EGFR antibody conjugated gold nanoparticles. Cancer Letters 239: 129-135.

69. Huang $X$ (2007) The potential use of the enhanced nonlinear properties of gold nanospheres in photothermal cancer therapy. Lasers in Surg Med 39: 747-753. 